\title{
Democracia e conquista: Saúde Mental como política pública municipal
}

\section{1 Jonathan G. Filippon, ${ }^{2}$ Luciane Prado Kantorski, ${ }^{3}$ Toyoko Saeki |}

Resumo: A Reforma Psiquiátrica brasileira é parte integrante da construção da democracia no Brasil e a Constituição Nacional de 1988 marca a descentralização política e financeira em direção aos municípios da federação. A pesquisa é qualitativa e objetiva analisar o processo democrático de construção, implantação e a aplicabilidade de uma Lei Municipal de Saúde Mental frente às contradições do processo social de reforma psiquiátrica brasileiro. Metodologia: triangulação de dados entre entrevistas com gestores (2), trabalhadores (5) e usuários (2) envolvidos com a política de saúde mental do município; observaçōes registradas em diário de campo (18 horas em 6 turnos alternados); e análise de documentos públicos. Análise dos dados: pela característica da hipótese, optou-se pelo referencial materialista histórico e dialético, dividindo a análise em duas etapas cronológicas - de 1989 a 1996 (promulgação da legislação municipal) e de 1996 a 2007 (implantação dos serviços). Conclusōes: a legislação municipal reformista de saúde mental é necessária enquanto garantia legal de direitos, mas a mesma possui sentido apenas se agregada à história que a produziu; é preciso aproximar-se da condição humana inerente às produções sociais para reproduzir nos novos trabalhadores de saúde o sentido da existência de movimentos sociais como a reforma psiquiátrica.

> Palavras-chave: democracia; Saúde Mental; políticas públicas.

\author{
1 Queen Mary \& University of \\ London, Centre for Primary \\ Care and Public Health. \\ Londres, Inglaterra. Endereço \\ eletrônico: jonathanfilippon@ \\ gmail.com \\ 2 Universidade Federal \\ de Pelotas, Faculdade de \\ Enfermagem. Pelotas-RS, \\ Brasil. Endereço eletrônico: \\ kantorski@uol.com.br \\ ${ }^{3}$ Universidade de São Paulo, \\ Faculdade de Enfermagem de \\ Ribeirão Preto. Ribeirão Preto- \\ SP, Brasil. Endereço eletrônico: \\ maryto@eerp.usp.br
}




\section{Introdução}

A Reforma Psiquiátrica brasileira foi, e ainda é, construída por inúmeras biografias, histórias da vida de pessoas que, no decorrer do processo, inverteram, subverteram e vivenciaram papéis sociais em todas as esferas da sociedade brasileira. Pelas significativas experiências sociais, multiplicadas a partir da reforma psiquiátrica brasileira - esta corroborada pela promulgação da Lei Complementar $\mathrm{n}^{\circ} 10.216 / 2001^{1}$ (BRASIL, 2001) -, as formas de relação entre a sociedade brasileira e a loucura estabeleceram novos significados, num processo dialético e histórico.

A descentralização do poder público em direção aos poderes locais nos municípios e seus cidadãos é o horizonte constitucional apontado em 1988 e direciona as políticas públicas a partir daquele ano até o presente momento. Em consonância com o cenário de descentralização de poder e recursos em saúde, proposto no final da década de 1980, o governo do Estado do Rio Grande do Sul aprovou, em 1992, a Lei Ordinária n 9.716/92, que dispõe sobre a Reforma Psiquiátrica no Estado do Rio Grande do Sul (RIO GRANDE DO SUL, 2008). ${ }^{2}$ Essa lei determina o fechamento paulatino dos leitos em hospitais psiquiátricos, concomitantemente à abertura de serviços alternativos ao manicômio, propondo que estes atuem em rede integrada, vedando a ampliação/abertura de leitos em hospitais psiquiátricos no estado. O recém-transposto marco de 20 anos de existência da primeira legislação estadual reformista em saúde mental no país justifica a relevância do seu registro histórico.

No ano de 1996, favorecidos pelo cenário de atores locais ativos nas discussões a respeito da Reforma Psiquiátrica brasileira, dois municípios da fronteira oeste do Estado do Rio Grande do Sul aprovaram legislaçôes municipais ecoantes à reestruturação do modelo de atendimento em saúde mental.

O objetivo geral do estudo foi analisar o processo democrático de construção, implantação e a aplicabilidade da Lei Municipal de Saúde Mental de uma cidade brasileira frente às contradições do processo social de reforma psiquiátrica nacional. Estabeleceu-se como objetivo secundário ou desdobramento da pesquisa a discussão do processo social e político de implementação da lei municipal de saúde mental do local estudado. 


\section{Métodos}

Esta é uma pesquisa exploratória que mescla elementos narrativos por conta do processo histórico descrito per se e crítica, ao apontar os efeitos do movimento de fluxo e contrafluxo dos acontecimentos na história e nos indivíduos envolvidos no fenômeno pesquisado. A pesquisa qualitativa explora significados, variações e experiências na percepção de determinados fenômenos (SILVERMAN, 2013), podendo ser aliada às concepções filosóficas do materialismo histórico para investigar transformações sociais promovidas pela capacidade única do homem em intervir na realidade coletiva, sendo concomitantemente moldado por tais ações enquanto indivíduo e sociedade (AGOSTINONE-WILSON, 2013). Os eventos envolvidos nos fenômenos ditos sociais, sejam eles de que natureza forem, são prenhes de significados e de intencionalidades, estes sendo inerentes à transformação de atos, relações e das estruturas sociais propriamente ditas, construídas e transformadas pela própria condição humana (MINAYO, 2006). O presente estudo utilizou o referencial teórico materialista-dialético para orientar todos os momentos da pesquisa, opondo-se à lógica linear dita idealista, em que a realidade é preconcebida seguindo preceitos previamente estabelecidos e definições não mutáveis. O homem transforma e é transformado por sua realidade, numa relação dialética e não necessariamente lógica do ponto de vista filosófico (ARTHUR, 2004).

Os dados foram coletados a partir dos seguintes instrumentos: observação, análise documental e entrevistas semiestruturadas. Inicialmente, foram realizados a exploração do campo de estudo, contato prévio com o campo, visita aos serviços da rede de saúde mental, proposição do estudo, busca dos documentos compatíveis com os objetivos da pesquisa e identificação dos sujeitos do estudo, agendando entrevistas. A observação foi realizada em seis turnos alternados, aleatoriamente, de três horas cada, totalizando 18 horas. Foi utilizado um diário de campo, a fim de registrar impressóes obtidas nos turnos de observação. Os documentos utilizados pela pesquisa foram: atas de reunióes relevantes ao tema, registros da Câmara Municipal de Vereadores de Alegrete e a Lei Municipal de Saúde Mental de Alegrete. A intenção foi a exploração máxima da triangulação entre os três métodos de coleta de dados: entrevistas, observação e levantamento de documentos relevantes. Para Denzin (1973), toda a triangulação de métodos e técnicas favorece a qualidade e a profundidade das análises. 
As entrevistas foram do tipo semiestruturadas, sendo registradas por equipamento de áudio e posteriormente transcritas na íntegra, possibilitando a organização dos dados coletados para análise. Optou-se por diferentes roteiros de entrevista para cada categoria de entrevistado, pelo entendimento de que o processo a ser estudado é coletivo, mas formado por diferentes atores sociais. Os sujeitos entrevistados na pesquisa foram elencados de acordo com a complexidade do Sistema Único de Saúde do Brasil:

- Gestores: entrevistaram-se gestores de saúde do município de Alegrete no período da coleta de dados: o secretário municipal de Saúde e o coordenador do Sistema de Saúde Mental.

- Trabalhadores em Saúde Mental: por meio de levantamento inicial, soube-se que existiam 27 trabalhadores em saúde mental no município; destes, cinco participaram do processo de implantação da Lei Municipal de Saúde Mental, sendo selecionados para entrevista.

- Usuários: dois usuários foram entrevistados a partir de sua participação no processo de implantação da Lei Municipal de Saúde Mental.

Optou-se, para a manutenção do sigilo dos entrevistados, pelo uso de pseudônimos. "Pessoa", "Blake", "Florbela", "Whitman", "Anjos", "Caeiro", "Rilke", "Reis" e "Gregório" substituem os nomes reais das pessoas ouvidas por esta pesquisa em sua fase de coleta de dados. Sua grafia no texto sempre aparece em destaque (caixa alta e itálico) para que possam ser diferenciados das citaçôes de autores reais. A transcrição dos dados de áudio foi impressa integralmente e analisada, classificando as falas de acordo com o momento histórico ou categorias que se apresentaram em mais de um ator social, conforme observado na apresentação dos resultados. Tanto as categorias criadas quanto as definiçōes dos momentos históricos emergiram da análise exaustiva dos dados transcritos e de sua relação com a opção teórica seguida por este estudo - o materialismo histórico e dialético proposto por Karl Marx.

O objeto deste estudo, a Legislação Municipal de Saúde Mental de Alegrete, é uma produção social, histórica e uma consequência real da dialética histórica dos processos nacionais de Reforma Psiquiátrica no Brasil. A concepção marxista possui uma teoria científica da história, denominada materialismo histórico e uma teoria filosófica também da história, o materialismo dialético. $\mathrm{O}$ materialismo histórico é a demonstração de que o real é passível de transformação pela ação humana. O materialismo dialético é a abordagem metodológica para a 
compreensão deste real, para tanto busca captar os vetores do real - dinamismo,

historicidade, provisoriedade, transformação; e, nesta captação, apreender os processos da prática social empírica dos indivíduos em sociedade e suas lutas de classes produtivas (EGRY, 1994; MINAYO, 2006).

As relações de trabalho e os meios de produção têm papel fundamental nesses processos. O marxismo permite compreender que os fatos humanos são historicamente determinados e que o conhecimento e análise de tais fatos permitem o uso racional dessas informações na busca de melhorias da própria condição humana (CHAUÍ, 1995). A economia possui papel fundamental nesse processo, provocando abalos e movimentaçôes em todos os aspectos da vida organizada em sociedade: artes, normas (aspectos jurídicos), crenças (aspecto religioso) e valores morais (GIOVANNI, 1984). As contradições presentes na existência social humana, geradas a partir das relações entre seus componentes, são o próprio motor da história. É possível alcançar maior compreensão dos fenômenos sociais por meio da análise de múltiplos prismas organizados em um discurso dialético: ao considerar os aspectos históricos de construção da relação entre as diferentes classes sociais; ao entender que a gênese das contradições entre classes sociais são as relações de produção; ao levar em consideração para análise o todo e não apenas parte do objeto de estudo; ao não isolar o fenômeno e considerá-lo sempre como parte de um todo, histórico e socialmente construído. Ao empreender a construção dialética em sua forma escrita, a compreensão e a capacidade de análise do estudo se alargam, senão atingindo a totalidade do objeto de estudo (o que talvez seja humanamente impossível), ao menos aproximandose em grande parte de sua complexidade. Para a construção dialética, há que se considerar, necessariamente, a historicidade do objeto estudado, em todas as suas contradições e vetores (ANDERY et al., 1988).

É importante ressaltar que

[...] a dialética não dá "boa consciência" a ninguém. Sua função não é tornar determinadas pessoas plenamente satisfeitas com elas mesmas. O método dialético nos incita a revermos o passado à luz do que está acontecendo no presente; ele questiona o presente em nome do futuro, o que está sendo em nome do que "ainda não é" (KONDER, 1982, p. 84).

Portanto, justamente por serem os homens os investigadores científicos, possuírem valores e vontades, e estes serem construídos a partir de sua história e da coletividade na qual estão inseridos, não há conhecimento asséptico. $\mathrm{O}$ 
pesquisador influencia sua pesquisa já a partir da escolha do objeto a ser estudado, da mesma forma que o objeto estudado age sobre o pesquisador (García, 1989). O ser humano é histórico, social e protagonista de sua história, influenciando diretamente nos rumos desta. Portanto, é necessário compreender o papel que a capacidade humana de produção a partir da intervenção na natureza possui neste processo. A isso chamamos trabalho, e

[...] foi com o trabalho que o ser humano "desgrudou" um pouco da natureza e pôde, pela primeira vez, contrapor-se como sujeito ao mundo dos objetos naturais (KONDER, 1982, p. 24, grifos nossos).

Marx buscou um entendimento da história, estrutura e dinâmica da sociedade utilizando uma delicada e minuciosa análise social, à qual dedicou a vida desenvolvendo um método científico que atingisse seus propósitos. Não chegou a produzir nenhuma obra específica sobre sua metodologia, mas esta emerge de sua produção literária claramente a ponto de se tornar um método de construção científica, que historicamente édenominado materialismo histórico dialético. Fruto do desenvolvimento de suas pesquisas relacionadas ao entendimento do funcionamento da sociedade, pode ser denominada também como concepção marxista da sociedade. Incutiu na análise dialética hegeliana a necessidade da fluidificação de seus conceitos, no sentido de que estes deveriam fluidificar-se entre os meandros sociais e não permanecer na realidade etérea do pensador. Marx propunha a fluidificação dos principais pressupostos necessários ao método materialista: a historicidade, a totalidade, a inter-relação, a alienação a partir da atividade laboral e a luta de classes entre os detentores dos meios de produção e os trabalhadores (KONDER, 1982). Segundo Marx, "a questão se cabe ao pensamento humano atingir uma verdade objetiva não é teórica mas prática”. Em outras palavras, não basta interpretar o mundo - é necessário transformá-lo. Marx coloca o homem racional-idealista de cabeça para baixo. E afirma: "não é a consciência dos homens que determina sua existência, mas, ao contrário, é a sua existência social que determina a sua consciência" (COTRIM, 1996, p. 253, grifos nossos).

Para Hegel, que primeiramente propôs a contradição no método dialético, esta vai além da simples concepção metafísica da contradição lógica. "A dialética não se contrapõe à lógica, mas vai além da lógica, desbravando um espaço que a lógica não consegue ocupar” (KONDER, 1982, p. 49). Para atingir tais espaços, Marx propõe a fluidificação dos conceitos apontados por Hegel: acreditava que Hegel era 
um idealista e ele próprio um materialista, não aceitando a realidade asséptica e idealizada por seu predecessor. A totalidade da realidade é complexa, histórica e construída entre as idas e vindas resultantes das lutas de classes estabelecidas pelos processos de produção e trabalho - por isso a expressão do filósofo alemão de "virar o homem racional-idealista de cabeça para baixo". Portanto, os pressupostos para análise dialética necessariamente haviam que transitar na realidade corrente, não dialogando apenas com as funções naturais do homem. Marx acreditava que Hegel pintava um quadro excessivamente abstrato em suas teorias, que se distanciava da totalidade da história humana (KONDER, 1982).

Conforme mencionado anteriormente, talvez não seja possível contemplar todos os vetores existentes na motricidade da história em uma só pesquisa, mas acreditamos que a metodologia proposta por Marx é a mais abrangente no sentido da compreensão da dinâmica dos fenômenos sociais analisados neste estudo. Nenhuma análise social relevante pode ser anistórica. As contradições presentes no passado são o motor dos acontecimentos presentes e tênues linhas para se pensar o futuro. A história é feita de, por e para os homens, e as relações sociais dinamizam os fatos históricos. "Na produção social da própria vida, os homens contraem relaçôes determinadas, necessárias e independentes de sua vontade" (MARX, 1974, p. 135). Para a construção dialética, há que se considerar, necessariamente, a historicidade do objeto estudado, em suas contradições e vetores, assim como as variadas construçôes da realidade individual que formam a história da sociedade contemporânea (BHASKAR, 2008), conforme nossos dados apresentam, ainda que de maneira limitada.

\section{Apresentação dos resultados \\ $O$ processo democrático}

Os municípios brasileiros precisavam sustentar o processo de descentralização econômica/administrativa/política proposto pela nova constituição de 1988 (DORIA, 1992) e, para tanto, muitos realizaram concursos públicos nessa época em variadas áreas de seus quadros de pessoal - nestas incluindo a saúde. Novos postos de trabalho surgiam para novos e experientes trabalhadores em saúde, que vivenciavam in loco as transformaçôes do final do regime militar, ainda marcados pelo período repressivo presente em suas histórias de vida neles mesmos ou em seus pais e familiares. A entrada desses profissionais nos 
quadros municipais desestabilizou cristalizaçōes do ente público e oxigenou as prefeituras que propuseram concursos públicos naquele momento. PESSOA relata este período:

[...] em seguida a Secretaria de Saúde, a prefeitura montou... estava montando o quadro para a saúde, botou no concurso público o cargo [...], e eu fiz o concurso, passei no concurso e fui chamada [...] (PESSOA).

Para Sartre (2008), a liberdade é a base da existência humana. O denominado pela teoria sartreana de ser-para-si define-se como poder de ação. Como précondição do ser-para-si e sua ação: a liberdade, dada ao homem por sua existência no mundo. $\mathrm{O}$ filósofo prescinde de qualquer valor moral que não seja criado pelo próprio homem - "o homem é inteiramente responsável por aquilo que é" (CHAUÍ, 1984b, p. 11). Como os acontecimentos políticos demonstram que os projetos de vida são influenciados pela história, e que esta é a história da própria coletividade, a tentativa de busca pela liberdade visando apenas a valores/metas individuais é inócua. Neste ponto, a teoria sartreana conflui para este objeto de estudo: somente um compromisso com a história pode fornecer sentido à existência individual, equação correspondente ao início da década de 1990 na cidade de Alegrete. FLORBELA ilustra:

[...] com uma inquietação enorme, vindo de uma cidade como a nossa, querendo trabalhar... E se incomodando. Eu logo que comecei a trabalhar já comecei a me incomodar muito com a forma com que eram tratados os portadores né... de deficiência. E aí nesse período, acho que em 1989, é, em 1989, foi aberto. Iniciou o processo de descentralização do sistema, de orientação em termos de saúde, com o Sistema Único de Saúde [...] É a redemocratização acontecendo... E aí houve... Eu já participava na universidade de movimentos políticos. (FLORBELA).

O momento histórico era propício a questionamentos sobre as formas de ser/fazer/trabalhar a Saúde Coletiva. O início da década de 1990 marca o princípio da legitimidade legal do Sistema Único de Saúde brasileiro, marcado pela promulgação da Lei no 8.080/90 (BRASIL, 1990). À reunião multiprofissional nos quadros das prefeituras que realizaram concurso para área da saúde no final da década de 1990 somam-se: a inexistência dos serviços de especialidades clínicas; a débil legislação em saúde vigente até a promulgação da Lei no 8.080/90 e suas respectivas portarias regulatórias; a quase inexistência de serviços de atenção básica à saúde na maior parte dos municípios brasileiros. 


\section{O cenário alegretense, a busca pela fertilidade democrática}

O município de Alegrete é caracterizado por marcas culturais extremamente arraigadas, ligadas diretamente às questôes de gênero de origem conservadora. As crenças sociais machistas são compartilhadas e reproduzidas por homens e mulheres, reforçadas pelo aspecto militaresco ${ }^{3}$ da cidade somado à figura do homem do campo, do gaúcho das estâncias. ${ }^{4}$ Este constructo fornece nuances peculiares ao cidadão local e a sua maneira de viver. Porém, a história relatada e analisada neste trabalho é praticamente toda executada por mulheres alegretenses. Profissionais da saúde, usuárias, gestoras, confundindo e entrelaçando esses papéis ao longo de suas vidas. Esta questão permeia toda a pesquisa - o protagonismo feminino frente aos processos sociais.

Após a aproximação junto ao Programa de Atenção Integral de Saúde Mental da Secretaria de Saúde do estado, os profissionais alegretenses foram, por sugestão desta secretaria, até a cidade de Uruguaiana. O fato foi assim registrado no livro-ata de reunióes (p. 1): "Visita ao ambulatório de Psiquiatria do Centro de Saúde de Uruguaiana”. Uma semana depois, no dia 18 de julho de 1989, a equipe se reuniu novamente e iniciou a montagem do primeiro Plano Geral de Saúde Mental para o município de Alegrete, conforme registro em ata presente no mesmo livro. Esta data ficou marcada historicamente como o ato de fundação do serviço de saúde mental de Alegrete, aniversário comemorado pelos trabalhadores e usuários até hoje.

Então tem uma construção muito bacana né, e a [...] eu acho que participava do governo na época, e eles tinham o programa né... De PAIS mental né, o Programa de Atenção Integral em Saúde Mental... Que foi o desencadeador desses processos nos municípios... Bagé, Alegrete, Alegrete foi depois até de Uruguaiana. Mas assim, o pessoal aprendeu, foi lá em Uruguaiana, eu lembro que a gente tem registrado no livro. Dia 11 de julho foi a Uruguaiana e dia 18 se reuniram aqui. Então a gente escolheu essa data, aonde foi reunida toda a equipe multidisciplinar para marcar como o aniversário do serviço. (WHITMAN).

Inicialmente instalados na casa que hoje é ocupada pela Décima Coordenadoria de Saúde do Estado do Rio Grande do Sul, a primeira equipe de saúde mental de Alegrete centrava seu trabalho na ótica comunitária, distando-se do referencial anterior, focado na instituição psiquiátrica. O lugar dos loucos, o hospício, começou a ser descaracterizado em forma de ações práticas, em ações clínicas de trabalho. Reescrever conceitos é uma das marcas dos processos reformistas psiquiátricos de cunho social (BORGES, 2007). 
Até então, a história da atenção à saúde mental no município de Alegrete tinha formas e açōes semelhantes a outros tantos processos ocorridos na mesma época de consolidação e construção inicial do SUS no país. A diferenciação se deu a partir da politização de seus agentes que, ao darem suas existências de encontro às dificuldades em lidar com a loucura de maneira institucional, buscaram outros conhecimentos que não apenas os referentes aos processos patológicos do sofrimento psíquico. A loucura é uma produção social, assim como seu território - o louco e o seu lugar, o hospício. O princípio da reterritorializaçãa $o^{5}$ da figura do louco na cidade de Alegrete começou nesse momento.

O que a gente via é que era... Que a gente era incapaz, a prática que a gente exercia dentro do ambulatório ou dentro do hospital ou dentro de uma clínica ou de um consultório era insuficiente para dar conta da necessidade de cuidado das pessoas. Então temos que mudar, tem que procurar outra coisa. Foi isso que fez com que... E aí a gente encontrar a proposta da saúde mental como um momento de buscar o diferente, construir a subjetividade, o sentido ou os sentidos né... Isso fez com que a gente se ressignificasse enquanto sujeito. (PESSOA).

\section{A construção político-partidária}

A necessidade de mais pessoas para o trabalho e a escrita biográfica dos atores da saúde municipal de Alegrete forçaram o chamamento de outros profissionais no começo da década de 1990, ainda oriundos do primeiro concurso público, após a nova Constituição de 1988, dando início a outra faceta desta história, a construção político-partidária.

Em conformidade com a construção e o estabelecimento da ideologia esquerdista formada no Partido dos Trabalhadores a partir de sua fundação em 1980, a década de 1990 foi profícua no tocante à explosão militante institucionalizada nesta sigla (KINZO, 2004). A escolha da institucionalidade deu-se a partir da ampliação de horizontes proporcionada pelos cursos de formação anteriormente citados. A escrita destes na biografia dos indivíduos participantes foi de tal sentido existencial que se tornou um dos eixos estruturantes da vida dos próprios indivíduos em questão: “[...] e o curso nos deu a visão política, a possibilidade de construção política, técnica... E administrativa da saúde coletiva (FLORBELA).

O ano de 1992 marcou historicamente a institucionalidade da reforma gaúcha com a promulgação da primeira lei estadual de reforma psiquiátrica do território nacional. Ela, em conjunto com a lei nacional que então tramitava e outras leis 

construção da lei municipal de Alegrete.

É todo um movimento do estado. Nós fizemos a nossa primeira conferência municipal de saúde mental em 92, o [...] [deputado estadual proponente da lei gaúcha de 1992] veio até Alegrete. Eu acho que foi a primeira assembleia que ele fez no Estado né, pela lei 9716 [Lei da Reforma Psiquiátrica Estadual] né... E nós estudando, lendo o estado e todos os materiais do curso. Chegamos à conclusão que nós não podíamos deixar o processo da saúde mental nas mãos do gestor. Ele tinha que ser da sociedade. Então, tinha que ser da sociedade... Então, como é que a gente faz pra responsabilizar a sociedade na construção de uma política? Então a gente primeiro costura... Primeiro a gente pega a lei do [...], que já tinha sido aprovada... Pega a lei do nosso companheiro lá de minas, o [...] Pega todas as leis de lá do Rio Negro e começa a ler aquilo né... E aí eu digo "olha, eu não entendo nada de política, nunca fui na Câmara de Vereadores, não tenho 'lhufas' de entendimento disso..." Mas a gente tinha uma certeza: tinha que ser a sociedade que tinha que mandar nesse troço, não podia ser a gestão. Porque a gestão faz se quer, não tem controle sobre ela. Então tinha que dar para a sociedade a responsabilidade de conduzir a política. E aí nós fizemos, lemos todo esse material e criamos uma lei nossa. Uma lei que falasse como é que é a política, de que jeito ela vai ser implementada, e por quem que ela vai ser tocada. (PESSOA).

Junto a esta evidência, que é parte integrante da participação democrática ativa, é necessária a coerência pessoal, neste caso personificada nas ações de trabalho em relação ao louco, estabelecendo o cuidado protagonista ao usuário do serviço local de saúde mental, influenciando diretamente no atrito de classes entre providos e desprovidos de recursos assistenciais/materiais. Este que, destituído de cidadania, como afirma Amarante (2008), sempre sujeitado pelas normas legais ou institucionais é, por si só, sujeito. Isso significa que, para além de mais uma norma (mesmo que esta seja reformista no sentido da inclusão social da loucura), é necessário junto dela dar voz a estes sujeitos, a estes loucos.

Eu quando falo do processo eu falo do processo dos sujeitos do Sistema Único de Saúde, não falo do sujeito técnico né... Teve, a participação dos técnicos foi muito importante, mas os usuários sempre estiveram conosco. Porque assim ó, uma das coisas que nós aprendemos em Bagé [nos cursos de formação], é que nós não fazíamos política para alguém. Nós fazíamos política para nós mesmos. Então a construção do "nós" era muito forte. Tanto que a primeira estratégia que propomos para transformar de ambulatório para serviço de atenção integral foi criar uma assembleia, onde os usuários, técnicos e gestores poderiam se encontrar semanalmente e decidir e planejar a semana. Quais seriam as ações, a gestão dessas ações, os responsáveis por essas ações e organizar as regras da casa. E acontece até hoje. Essa assembleia existe até hoje. No início era muito difícil porque o usuário não estava acostumado a se reunir em roda e debater, e ter ouvido para ele... e ter o seu encaminhamento como algo importante e de mudança né, na estrutura. Mas depois as pessoas foram se apropriando e se acostumando e agora não conseguem mais fazer se não for assim. Isso é bom né... (PESSOA). 
Do serviço de saúde mental alegretense originam-se mandatos de vereança, gestores municipais e mandatários do executivo municipal, além de candidaturas que disputaram (e disputam) eleições municipais e estaduais.

\section{E a lei se fez!}

A partir da consolidação das parcerias regionais e câmbios de experiência entre os profissionais de saúde fronteiriços, estabeleceu-se como estratégia fundamental de consolidação do processo reformista gaúcho o eco à lei estadual de Reforma Psiquiátrica de 1992. Em 1996, as cidades de Alegrete e Bagé promulgaram as primeiras legislações municipais de reforma psiquiátrica do estado do Rio Grande do Sul. No momento anterior à promulgação, os trabalhadores de saúde mental ainda não haviam exercido cargos legislativos ou na gestão do executivo municipal, além do próprio trabalho em saúde. As características dos serviços de saúde mental e a luta pela absorção social do sofrimento psíquico sem estigma evidenciaram, posteriormente, as pessoas que ali estavam trabalhando.

Nós temos uma caminhada muito grande. Ele funcionou como ambulatório... Né, depois ele avançou... O que nós chamamos de um serviço. Não existia essa regulamentação de Centro de Atenção Psicossocial [CAPS]... Não existia nada! Não existia nem financiamento... Né, em 91 nós, a militância nos lugares, locais... E a vontade política do gestor municipal é que garantiu o funcionamento do serviço. Porque tu não tinha financiamento, não é como hoje que tu tens um sistema $\mathrm{APAC}^{7}$ que financia os CAPS enfim... Não existia nada na época... Existia vontade local de organização do serviço né... Orientados por uma política estadual. Que era uma orientação mesmo... Que... O argumento, ele era tão forte, a construção teórica, política, do movimento social ele era tão forte que se convencia o gestor municipal a criar um serviço... Sem nenhuma especificidade de financiamento. Era a pressão do movimento... E acho que era o momento, o período que nós vivíamos de redemocratização ele também criava essa... Essa intenção política nos gestores... Mesmo os nossos aqui serem gestores muito conservadores [...] (FLORBELA).

Apesar da existência do serviço sem previsão de financiamento, uma conquista do movimento de saúde mental, havia necessidades municipais a serem contempladas que não poderiam ser deixadas ao sabor da gestão que estivesse à frente do poder executivo. Era preciso garantir o fluxo das internaçóes psiquiátricas, estritamente quando necessárias, e em hospital geral, legitimar o poder do controle social, criar uma comissão municipal de saúde mental dentro do Conselho Municipal de Saúde e garantir legalmente o tipo de trabalho a ser realizado nos serviços de saúde mental que futuramente viessem a ser criados - a posteriormente chamada clínica psicossocial. 
Então... A lei surge do nosso trabalho, e aí... A participação popular que dá susten-

tação... Mas a elaboração da lei... Foi uma coisa bem... De... Elaboração e avaliação nossa. Porque nós entendíamos que estava chegando ao fim um governo e que nós não podíamos ficar na dependência do estado, que perdeu muito com a saída da [...] e o governo que assumiu não valorizava... Que nós queríamos ter a sustentação local né... Trocando o governo nós termos uma legislação que impedia a instalação de serviços em hospital. Então foi uma ação militante. (FLORBELA).

\section{Os processos transformadores}

A partir do ano de 1996, com a orientação técnica do cuidado à loucura materializada na Lei Municipal no 2.662/1996, segue-se outra etapa na história da saúde mental do município de Alegrete. O interstício entre a lei municipal da cidade e a legislação nacional de reforma psiquiátrica foi marcado por conquistas pessoais e políticas dos trabalhadores em saúde mental que, pela exposição/ implicação ocorridas na defesa dos excluídos pela loucura, acabou alçando-os a outros horizontes políticos. Os enfrentamentos políticos de gestão e dos pleitos eleitorais demarcaram um diferencial da atenção à saúde mental em relação à atenção primária no município. Criou-se um terreno claro de militância e de conquistas, uma identidade de trabalho, muito próxima à ideia de democracia direta de Gramsci (1968) e Togliatti (1980). A forma de trabalho e o terreno de execução deste eram tão nitidamente diferenciados das outras ações pertencentes à mesma secretaria municipal (de Saúde) que, em um dado momento histórico, chegaram a ser confundidas administrativamente pelo gestor da época.

A saúde mental sempre foi colocada para... Como um divisor de águas. Quando se falava em Sistema Único de Saúde todo mundo lembrava era da saúde mental. Tanto que nós chegamos, teve uma época que todos os comprovantes de pagamento da secretaria de saúde diziam Secretaria de Saúde e os contracheques da saúde mental diziam Secretaria Municipal de Saúde Mental . Então tu identificava uma incapacidade do gestor de entender tanto o processo da saúde mental como do SUS. Era uma coisa à parte porque era visível o conceito né, de qualificação do Sistema Único de Saúde, de investimento no cuidador, de responsabilidade com a sociedade sabe? (PESSOA).

A separação administrativa demonstrada nos comprovantes de pagamento da época denota a incapacidade do gestor em entender o compromisso ético-político dos militantes da saúde mental no município.

O final da década de 1990 marcou um funcionamento com poucos recursos, quadro que mudaria sensivelmente apenas com a lei de Reforma Psiquiátrica nacional, no ano de 2001, a partir da regulamentação do financiamento de serviços 
substitutivos ao manicômio. A polarização entre a condição de ser militante e/ou trabalhador ampliou-se a partir do financiamento específico e da criação de novos serviços de acordo com a Portaria $\mathrm{n}^{\mathrm{o}} 336 / 2002,{ }^{8}$ na qual os postos de trabalho foram multiplicados, assim como os serviços. O Serviço de Atenção Integral em Saúde Mental passou a ser um Centro de Atenção Psicossocial, e houve a criação de novos serviços substitutivos: um Centro de Atenção Psicossocial Infantil, um Centro de Atenção Psicossocial para Álcool e Drogas e um Serviço Residencial Terapêutico. O serviço de saúde mental tornou-se então o Sistema de Saúde Mental, contando, além dos serviços substitutivos citados, com os plantōes de acompanhantes terapêuticos no Hospital Santa Casa de Alegrete para acompanhar as internaçôes que se mostrem necessárias. A institucionalidade garante vantagens administrativas e organizacionais que, se descoladas do processo histórico em que estão inseridas, perdem o sentido de conquista e de criatividade.

[...] se articulou a rede de um outro jeito, né... Hoje tu tens serviços de acompanhamento, acompanhante terapêutico dentro do hospital Então não é mais o terapeuta. [...] Existe muito mais estrutura, existem os plantões né, existem os acompanhantes terapêuticos dentro do hospital, mas acho que uma das coisas maravilhosas que nos constituiu como referência e que faz com que eu hoje entenda, possa discutir com um psiquiatra sobre a atenção, que eu possa discutir a medicação que ele está utilizando com o meu usuário, com aquele que eu estava acompanhando, exatamente era a responsabilidade que tu tinha ao assumir como terapeuta de referência. Que hoje não tem mais né... Então, eu quando ia pra dentro de um hospital acompanhar um fulano surtado eu tinha que dar conta, entendeu? Eu tinha que usar da minha criatividade, ali não era clínica... Era clínica, mas uma outra clínica...(FLORBELA).

Uma outra clínica, pessoal e de envolvimento, não um objeto de trabalho. O fenômeno local não é um privilégio, podendo ser observado empiricamente como uma dificuldade nacional da reforma psiquiátrica. Pessoas em sofrimento psíquico que necessitam ser cuidadas são o objeto de trabalho, porém é preciso considerar que mesmo nesta condição tal objeto ainda concerne diretamente à existência humana, portanto única. Ao institucionalizar os modos de cuidado à loucura, a clínica corre o risco de se repetir, conforme as identificações patológicas realizadas. Cria-se um cuidado à doença e não ao indivíduo, perdendo a noção proposta por Basaglia (1991) de deixar a patologia entre parênteses.

A partir da mudança do espaço físico e do distanciamento de outras formas de relação com a gestão, após as eleições municipais de 2000, surgem outras possibilidades institucionais. A partir de um cenário, inicialmente, de difícil 
ação, de poucos recursos e parca estrutura foi possível à equipe do serviço

de saúde mental traçar estratégias dentro de outro panorama de relação com o executivo municipal. $\mathrm{O}$ constructo do cenário de trabalho, somado à possibilidade de financiamento direto dos serviços, com a garantia de repasse da gestão local, alicerçados na experiência da clínica psicossocial desenvolvida até então pelos trabalhadores na década de 1990, culminou em uma massa crítica que expandiu o serviço anterior para um sistema de cuidado à loucura mais complexo e institucional - com todas as benesses e ônus que o processo de institucionalidade carreia. Descrita como processo histórico, perde-se a noção cronológica de que se passaram três anos, pelo menos, até que se resolvesse a situação de precariedade descrita.

Eu sei que aí nós trabalhamos eu acho que uns três anos nessa situação precária assim... Mas sempre negociando, sempre contando muito com a comunidade, contando muito com os usuários... E nós já trabalhávamos como hoje são os Centros de Atenção Psicossocial. Então assim, nós tínhamos refeições, nós tínhamos oficinas... Nós tínhamos atendimento em grupo. (CAEIRO).

A equipe não encontrava ressonância local na região ou no estado para respaldar suas ações e projetos. A maioria dos entrevistados classificou como ausente a Coordenação estadual de Saúde Mental, a partir de 2000, dada a não participação dos processos locais de implantação dos serviços a partir deste ano. O papel do ente estadual no SUS ultrapassa o de cofinanciador, na medida em que deveria exercer a função de mediador entre trabalhadores e gestão, seguindo as diretrizes nacionais. Observa-se, empiricamente, um esvaziamento do papel do ente estadual a partir da municipalização dos serviços, deixando à deriva cargos como a gestão estadual de saúde mental - elos essenciais entre os municípios e o ente federal.

Então tudo isso assim enquanto Estado, se tu não fosse ficar nessa crítica do Estado [ente estadual], tu não consegue trabalhar a região. $\mathrm{E}$ as regionais ficam paradas né. É o que a gente tem hoje, a nível de regional tu consegues muito pouca influência nos municípios. Agora a nível federal, o que a gente começou a notar: que tu mandava as coisas... E vinham. E quando veio a portaria aquela dos CAPS, a 336, a gente foi um dos primeiros municípios a cadastrar o CAPS. Porque a gente já funcionava como CAPS. Nós já tínhamos equipe de CAPS, já tínhamos serviço de CAPS, nós já tínhamos tudo... Tudo que precisava... Nós tínhamos a associação, nós tínhamos os lares, nós tínhamos... Tudo que precisava né, a gente tinha. Aí eu acho que foi um dos primeiros serviços assim que se cadastrou. (CAEIRO).

A partir do cadastramento do Centro de Atenção Psicossocial (CAPS) de Alegrete, era preciso sensibilizar o gestor da época para efetivar o repasse dos 
recursos que vinham do governo federal. Há, por parte de muitos gestores, o desconhecimento das origens e possibilidades de recursos disponibilizados pelo Ministério da Saúde para os municípios brasileiros. No caso de Alegrete, o gestor acreditava que o dinheiro a ser disponibilizado seria descontado do montante que era fornecido para a atenção básica do município.

E aí o nosso gestor, ele disse "ah, esse dinheiro estão tirando da atenção básica, e ele está indo pra vocês, agora vocês vão ter dinheiro e a atenção básica vai ficar sem dinheiro". Eu fiquei uma fera né, aí, "eu disse então tá, nós vamos fazer o seguinte: nós vamos lá na coordenadoria, conversar com o pessoal de lá, e eles vão te dizer de onde vai sair este dinheiro. Só que tu vais me prometer uma coisa: se este dinheiro não for da atenção básica, for um dinheiro "extra", todo dinheiro que entrar tu vais investir na saúde mental. Isso é um compromisso teu: todo centavo que entrar nosso agora tu vais investir na saúde mental. (CAEIRO).

A partir do compromisso da gestão, o serviço de saúde mental, agora um CAPS, começou a receber recursos e planejar a aplicação do montante disponibilizado pelo Ministério da Saúde. A responsabilização pela estrutura de trabalho era calcada no movimento social preexistente, materializado na lei municipal de saúde mental. A partir da legislação federal, os trabalhadores puderam concretizar açôes e aumentar a complexidade e especificidade dos aparelhos de cuidado à loucura.

[...] e aí tá, nós começamos a trabalhar... E recebíamos um bom dinheiro, e esse dinheiro assim ó... Nós reformamos todo o CAPS, nós começamos a construir a residência terapêutica, claro, isso aí tudo com a luta das pessoas né, da sociedade, ação... Dos movimentos, dos usuários... Tudo assim, um trabalho bem integrado como uma coisa política, quando a gente precisava de alguma coisa... Muito bem articulado, todos os movimentos com o conselho né, com a câmara... (CAEIRO).

A partir de 2002, o serviço de saúde mental foi transposto para um sistema complexo, contando com um Centro de Atenção Psicossocial para Álcool e Drogas (CAPS ad), um Centro de Atenção Psicossocial Infantil (CAPSi), um Residencial Terapêutico, uma Moradia Assistida e o serviço de Acompanhantes Terapêuticos para as internações, quando necessárias, no Hospital Santa Casa de Alegrete. Todos esses serviços foram oriundos do CAPS II, este cumprindo o papel de catalisador da rede de saúde mental: “[...] o CAPS II cumpre a função que a gente propõe mesmo, que o CAPS seja um laboratório... Um laboratório de projetos, um desencadeador de processos" (REIS). 


\section{Considerações finais}

Após a aproximação dos dados colhidos em campo de pesquisa, ressalta-se que a lei reformista de saúde mental em nível municipal é um marco histórico de garantia de direitos no caso estudado. Ao direcionar, em uma lei, a característica de entendimento da loucura como um fenômeno a ser discutido, tratado, entendido em aparelhos substitutivos ao modelo manicomial, cursos de vida foram alterados. Os loucos não são mais drenados ao manicômio. Mesmo que os artigos da lei não sejam utilizados direta e cotidianamente pelos atores sociais envolvidos com a questão, podendo desconhecer suas palavras inclusive, tal lei, ao fornecer um direcionamento de gestão, atua diretamente na biografia dos cidadãos alegretenses que estejam de alguma forma envolvidos no processo social da loucura. Portanto, ao normatizar a não aplicação de dispositivos manicomiais na cidade, uma lei municipal de saúde mental influencia diretamente os aspectos da gestão de saúde pública local e do entendimento social acerca da loucura. $\mathrm{O}$ direcionamento dado pela legislação é perene em relação às oscilações de gestão fornecidas pelo processo democrático de disputa eleitoral. Há que se ressaltar, no entanto, que a inovação, o que está além dos artigos da lei, dá-se pelos humanos que, ao compartilharem valores comuns, suportam, em ações práticas, as oscilações determinadas pelas mudanças de gestão.

Os achados deste estudo demonstram que, quando as ações de clínica psicossocial não estão ainda amarradas legalmente ao financiamento estatal, a necessidade criadora torna-se maior, ampliando o horizonte de possibilidades. Porém, tais ações se tornam pessoalizadas e pontuais, já que se distanciam da noção de política coletiva, que deveria agregar novos atores de maneira horizontal. Açōes militantes, necessárias ao protagonismo das políticas públicas inovadoras, neste caso em relação à não estigmatização da loucura, diferem das ações de trabalho. Porém, para que a questão entre a militância e o trabalho não seja um estagnador dos processos sociais e o financiamento público uma amarra ao processo criativo de gestão, a institucionalidade de trabalhadores/militantes e políticas públicas não deve ser perversamente descolada dos processos históricos em que estão inseridos.

O trabalho de cuidar a loucura de forma não estigmatizadora é um constructo estético criado a partir de uma ruptura histórica em direção a valores humanistas. Portanto, trabalhar com saúde mental é, necessariamente, romper o estigma da 
loucura moralizante e cega, do ponto de vista da valorização da existência humana. A atuação em saúde mental pressupõe um rompimento histórico e fornece sentido aos recursos financeiros hoje previstos nas portarias federais de financiamento dos serviços substitutivos ao manicômio. É necessário aproximar os valores agregados a este rompimento histórico dos novos trabalhadores em saúde mental, não esperando a formação de militantes, visando, sim, a um trabalho pertencente ao seu momento histórico, que pertença ao seu tempo, não repetindo erros já cometidos e identificados. A história da sociedade humana ocidental e eurocêntrica produziu a figura do louco e do seu território, e esta mesma sociedade supera, em cada serviço substitutivo, criado ou instituído, conhecidos mecanismos de exclusão e reprodução da loucura moral. Fazer com que os reprodutores destes mecanismos excludentes não sejam os próprios trabalhadores em saúde mental é aproximá-los da história, é fornecer sentido ao trabalho e à existência destes em seus papéis sociais.

Este trabalho de pesquisa visa à exposição do fenômeno da loucura produzida socialmente, além de destacar a capacidade humana de, ao politizar-se, tomar para si as rédeas da história. Busca demonstrar, ainda, que os fatos sociais não estão pré-ditos historicamente, mesmo que os homens façam suas escolhas existenciais situados em determinado momento histórico. Este é um trabalho do seu tempo, fruto da própria contradição do modelo manicomial de exclusão da loucura.

Os manicômios físicos e mentais, ao demonstrarem historicamente sua total incapacidade de reabilitar socialmente o louco, de normatizá-lo, produziram a necessária contestação, materializada pela Reforma Psiquiátrica. Trabalhouse aqui a exposição do humano presente, necessariamente, na loucura. Não ter razão, no sentido cartesiano da racionalidade, é criar; é fazer arte; é fugir à técnica; é ser, essencialmente, humano.

\section{Referências}

AGOSTINONE-WILSON, F. Dialectical research methods in the classical Marxist tradition. Oxford: Peter Lang Publishing, 2013.

AMARANTE, P. O homem e a serpente. 3a ed. Rio de Janeiro: Fiocruz, 2008.

ANDERY, M.A. et al. Para compreender a ciência. São Paulo: EDUC, 1988.

ARTHUR, C.J. The New Dialectic and Marx's Capital. Boston: Brill, 2004.

BASAGLIA, F. A instituição negada: relato de um hospital psiquiátrico. 2a ed. Rio de Janeiro: Graal, 1991. 
BHASKAR, R. The pulse of freedom. London: Routledge, 2008.

BORGES, C.F. Politicas de Saúde Mental e sua inserção no SUS: a discussão de convergências e divergências e o resgate de alguns conceitos e valores pertinentes à Reforma Psiquiátrica. Dissertação (Mestrado em Saúde Pública) - Escola Nacional de Saúde Pública Sérgio Arouca, Fundação Oswaldo Cruz, Rio de Janeiro, 2007.

BRASIL. Gabinete da Presidência da República. Lei Complementar no 8.080, de 19 de setembro de 1990. Dispõe sobre as condições para a promoção, proteção e recuperação da saúde, a organização e o funcionamento dos serviços correspondentes e dá outras providências. Brasília, 19 setembro de 1990. Disponível em: <http://portal.saude.gov.br/ portal/arquivos/pdf/lei8080.pdf> Acesso em: 07 jan. 2013.

. Lei $\mathrm{n}^{\circ} 10.216$, de 06 de abril de 2001. Dispõe sobre a proteção e os direitos das pessoas portadoras de transtornos mentais e redireciona o modelo assistencial em saúde mental. Diário Oficial [da] República Federativa do Brasil, Brasília, DF, 09 abr 2001. Seção 1, p.2.

CHAUÍ, M. Os Pensadores: Sartre. Prefácio, vida e obra de Jean Paul Sartre. São Paulo: Abril, 1984.

. Convite à Filosofia. 2a ed. São Paulo: Ática, 1995.

COTRIM, G. Fundamentos da Filosofia. 12a ed. São Paulo: Saraiva, 1996.

DENZIN, N.K. The Research Act. Chicago: Aldine, 1973.

EGRY, E.Y. Elementos teórico-metodológicos para a intervenção prática da enfermagem em saúde coletiva. 205p. Tese (Livre-Docência) - Escola de Enfermagem da Universidade de São Paulo, São Paulo, 1994.

NUNES, E.D. (Org.). Juan Cesar García: pensamento social em saúde na América Latina. São Paulo: Cortez, 1989.

GIOVANNI, G. O Método Dialético. In: SEMINÁRIO NACIONAL DE PESQUISA EM ENFERMAGEM. 3., Florianópolis, 1984. Anais..., p. 161-171.

GRAMSCI, A. Maquiavel, a política e o Estado moderno. Rio de Janeiro: Civilização Brasileira, 1968.

GUATTARI, F. As três ecologias. Campinas: Papirus, 1993.

KINZO, M.A. Partidos, eleições e democracia no Brasil pós-1985. Revista Brasileira de Ciências Sociais. São Paulo, v. 19, n. 54, p. 23-40, 2004.

KONDER, L. O que é a dialética. São Paulo: Brasiliense, 1982.

MARX, K. Para a crítica da economia política. In: Os Pensadores. São Paulo: Abril, 1974.

MINAYO, M.C. de S. O desafio do conhecimento: pesquisa qualitativa em saúde. São Paulo: Hucitec, 2006. 
RIO GRANDE DO SUL. Lei Ordinária n 9.716, de 07 de agosto de 1992. Dispõe sobre a reforma psiquiátrica no Rio Grande do Sul, determina a substituição progressiva dos leitos nos hospitais psiquiátricos por rede de atenção integral em saúde mental, determina regras de proteção aos que padecem de sofrimento psíquico, especialmente quanto às internações psiquiátricas compulsórias, e dá outras providências. Disponível em: <http://www.al.rs.gov.br/legis/M010/M0100099.ASP?Hid_Tipo=TEXTO\&Hid_ TodasNormas $=15281 \&$ hTexto $=\&$ Hid_IDNorma=15281 $>$ Acesso em: 07 jan. 2013.

SARTRE, J.P. O ser e o nada. Petrópolis: Vozes, 2008.

SILVERMAN, D. Doing qualitative research. London: Sage, 2013.

TOGLIATTI, P. Socialismo e democracia: obras escolhidas. Rio de Janeiro: Ilha, 1980.

\section{Notas}

${ }^{1}$ A Lei Federal no 10.216/2001 dispõe sobre a proteção e direitos das pessoas portadoras de transtornos mentais e redireciona o modelo assistencial em saúde mental no país (BRASIL, 2001).

2 A Lei Ordinária no 9.716/92 dispõe sobre a reforma psiquiátrica no Rio Grande do Sul, determina a substituição progressiva dos leitos nos hospitais psiquiátricos por rede de atenção integral em saúde mental, determina regras de proteção aos que padecem de sofrimento psíquico, especialmente quanto às internaçôes psiquiátricas compulsórias, e dá outras providências (RIO GRANDE DO SUL, 1992).

${ }^{3}$ A cidade de Alegrete possui cinco quartéis do Exército nacional, herança histórica da posição estratégica em relação às fronteiras do Brasil.

${ }^{4}$ As estâncias são como fazendas, diferindo no aspecto de que estas não priorizam o plantio e sim a criação de animais. Os trabalhadores desses locais usualmente cultivam as tradições culturais gauchescas, como a vestimenta típica para o trabalho, alimentação baseada na carne e arroz, gírias e sotaque muito próprio com influências diretas da língua espanhola.

5 O conceito de territorialidade, para Guattari (1993), é caracterizado por um fenômeno de origem psicológica, formado a partir de dimensões sociais e políticas. Afeta diretamente a percepção consciente dos sujeitos acerca do que se refere - neste caso, o território da loucura e do louco. Ou seja, territorialidade aqui diz respeito ao território de símbolos culturais e construções sociais referentes ao entendimento humano acerca da loucura, por isso seu território. Os conceitos derivados da territorialidade: desterritorialização, que compreende os mecanismos que separam o território simbólico de seus vínculos sociais e culturais; reterritorialização, que vem a ser a criação de novos vínculos (símbolos, crenças, entendimentos) em lugar dos destituídos pelo movimento desterritorializador.

"O termo "sentido existencial" refere-se ao homem e seu lugar no mundo, a partir das concepções de Sartre (2008). Para Sartre (2008), o lugar-no-mundo é a experiência existencial da consciência: o plano do pensamento deve ceder seu lugar a uma experiência existencial concreta - uma experiência que permita atingir o sentido da existência em seu ser-no-mundo (BORNHEIM, 2007, p. 19). Portanto, ao referir o sentido existencial fornecido pelos conhecimentos adquiridos nos cursos de formação, explicita-se que, ao atingir conscientemente conceitos como democracia, liberdade e participação política, os atores sociais alegretenses conciliaram seu lugar-no-mundo - alterando significativamente suas biografias. 
7 APAC - Autorização para Procedimento de Alto Custo. É a forma de financiamento permanente dos Centros de Atenção Psicossocial, regulada pelo número de vezes que o usuário comparece ao local de atendimento. Contraditoriamente, necessita de diagnóstico psiquiátrico para ser emitida. $\mathrm{O}$ repasse de recursos é realizado fundo-a-fundo, ou seja, em depósito direto do ente federal para a conta bancária do ente municipal. Esta relação de planejamento e financiamento deve ser regulada pelo controle social através do Conselho Municipal de Saúde (BRASIL, 2002).

${ }^{8}$ A Portaria Ministerial no 336/2002, do Ministério da Saúde, regulamenta a implantação e o financiamento dos Centros de Atenção Psicossocial no território brasileiro.

9 J.G. Filippon, autor principal, elaborou a pesquisa, trabalho de campo e redação do argumento original. L.P. Kantorski realizou edição e supervisão do argumento e da pesquisa. T. Saeki colaborou como supervisora da pesquisa. A pesquisa foi apoiada pela Coordenação de Aperfeiçoamento de Pessoal de Nível Superior (CAPES). 
Democracy and achievement: mental health as a municipal public policy

The Brazilian psychiatric reform is part of the construction of Brazil's democracy and the National Constitution of 1988 subscribes the politic and financial decentralization towards the nation's municipalities. This study reveals the country's democratization consequences in a Brazilian city in addition to the political characteristics of the psychiatric reform between 1989 until 2009. It is a qualitative research and aimed to analyze the democratic process of construction, implementation and applicability of a Municipal Law of Mental Health facing the contradictions of the Brazilian psychiatric reform processes, testing the hypothesis of necessity of a reformist mental health law at the municipal level. Methodology: interviews with managers (2), health workers (5) and users (2) involved with the mental health municipal policy; observations registered on a journal (18 hours divided in 6 alternate shifts); analysis of public domain documents. Data analysis: because of the hypothesis characteristics, the theoretical framework of historical and dialectical materialism was used in two chronological stages - from 1989 until 1996 (publication of the municipal law) and from 1996 until 2007 (implementation of services). Conclusions: the reformist municipal mental health law is necessary as a legal warrantee of rights, however, it only has meaning if summed to the history that has produced it; it is necessary to approach the inherent human condition of the social production to reproduce on the new health workers the meaning of existence of social movements such as the psychiatric reform.

> Key words: democracy; Mental Health; public policies. 